\title{
Research on the Developmental Stages of Zhejiang's Express Delivery Industry Based on the Logistic Growth Model
}

\author{
Xi Wang \\ School of Beijing Jiaotong University, Beijing 100044, China. \\ 16120891@bjtu.edu.cn
}

\begin{abstract}
Express delivery industry is formed of stages of the formation, development, maturity and other developmental status. The definition of its developmental stage makes it feasible to formulate more scientific and reasonable measures to promote better development of the express delivery industry. The logistic growth model is fitted with the data of Zhejiang' express delivery volume per capita from 2007 to 2017 . The results show that Zhejiang express delivery industry was in the stage of formation from 2007 to 2015 and was in the early growth stage from 2015 to 2017. It is predicted that the express delivery industry will be in the late growth stage from 2017 to 2019 and will enter the mature stage from 2019. Based on the conclusion, this paper makes suggestion aiming at the current situation to promote the sustained and healthy development of Zhejiang 'express delivery industry.
\end{abstract}

Keywords: Express delivery industry; logistic growth model; Zhejiang province.

\section{Introduction}

With the rapid development of the e-commerce, express delivery industry is booming and especially in recent years, the express delivery logistics demand has greatly increased while the ecommerce develops in a diversified, multi-level and multi-mode way. However, the express delivery industry is seriously affected by the social and economic environment, which is the reason why its growth process follows the developing law of social and economic. Based on the theory of demand hierarchy and demand elasticity, combined with the characteristics of express delivery industry, the product life cycle theory is introduced into the logistics to study the growth trend of express delivery industry development. Logistic growth model can better describe the Characterize the formation period, competition period, innovation period and evolution period of the express delivery industry which is in favor of grasping the growth and evolution process of express demand.

Relying on the advantages of high-speed development of e-commerce, Zhejiang is firmly in the forefront of the country in the aspect of developing express delivery industry in recent years. At the same time, express delivery service provides support for other walks of life and it plays a vital role in Zhejiang 'economic system. In terms of the local government, it is propitious to formulate targeted policies and make timely planning adjustments to understand the growth stages of the express delivery industry from the macroscopic perspective. On the other hand, following the industry tendency is conductive to optimize long-term investment structure and business composition for enterprises. In this paper, logistic growth model is used to study the development stage of Zhejiang's express delivery industry which accurately depicts the law of its industrial growth, and then effective countermeasures are formulated to promote further development.

\section{Methodology}

Logistic growth model which describes the S-type growth of population under the condition of limited environmental capacity takes advantage of mathematical methods. It can overcome the limitation of linear equation constrained by statistical assumptions and has the advantages of no strict assumptions, fixed growth rate and capacity parameters, which make it better to describe the growth law of industry. The theoretical model of Logistic function is expressed as:

$$
\frac{d y}{d t}=y r\left(1-\frac{y}{k}\right)
$$


Among the letters, $t$ denotes the time variable, $y$ denotes the population corresponding to the time point $\mathrm{t}, \mathrm{K}$ is the maximum environmental capacity, and $\mathrm{r}$ denotes the population growth rate.

Integral operation of formula 1 is done and arranged as follows:

$$
y=\frac{K}{1+a e^{(-r t)}}
$$

Among the letters, a is a limiting factor which has a certain inhibitory effect on its growth, also known as logistic coefficient, and $\mathrm{K}$ is the maximum environmental capacity.

The Logistic curve is monotonically increasing and there are two asymptotes: $\mathrm{N}=\frac{\mathrm{K}}{1+\mathrm{a}}$ and $\mathrm{N}=\mathrm{K}$.

When $\mathrm{N}<\frac{\mathrm{K}}{2}$, the graph is concave curve; when $\mathrm{N}>\frac{\mathrm{K}}{2}$, the graph is convex curve; when $\mathrm{N}=\frac{\mathrm{K}}{2}$, the graph is the only inflection point of the graph and the corresponding time point $\mathrm{t} *=\frac{\ln }{\mathrm{r}}$ when the growth rate is the fastest. And another two inflection points of the curve correspond to $t_{1}=\frac{\ln -1.317}{r}$ and $t_{2}=\frac{\ln a+1.317}{r}$. The growth process of biological population was divided into four stages by time point $t_{1}, t_{2}$ and $t *$ which showed different characteristics of population growth.

\section{Case Study}

\subsection{Data Processing}

There are many variables to describe the growth law of express industry, such as volume of express delivery, the number of employees, express delivery branch coverage and industrial income, among which volume of express delivery is the most directly that reflects the developmental reality of the industry. However, the large base of total express delivery volume is not conducive to grasp the developmental tendency of the industry, in order to more clearly describe the situation and future change, according to the principle of availability of data and the purpose of modeling, express delivery volume per capita per year as the indicators to characterize the growth of express demand.

The original data, Zhejiang 'annual volume of express delivery provided online, were collected from National Bureau of Statistics of China which issued in 2007 to 2017 and the number of permanent population was collected from Zhejiang Province Statistical Yearbook, and then we calculate the express delivery volume per capita over the years, as shown in Table 1.

Table 1. Zhejiang' express delivery volume per capita in 2007-2017

\begin{tabular}{|c|c|c|c|c|c|c|}
\hline Sequence number & 1 & 2 & 3 & 4 & 5 & 6 \\
\hline Year & 2007 & 2008 & 2009 & 2010 & 2011 & 2012 \\
\hline Zhejiang' express delivery volume per capita & 2 & 2 & 3 & 5 & 9 & 15 \\
\hline Sequence number & 7 & 8 & 9 & 10 & 11 & \\
\hline Year & 2013 & 2014 & 2015 & 2016 & 2017 & \\
\hline Zhejiang' express delivery volume per capita & 26 & 45 & 69 & 107 & 140 & \\
\hline
\end{tabular}

\subsection{Modeling}

The development of express delivery industry in Zhejiang Province is influenced by resource conditions, economic environment, technological innovation and other factors, therefore the express delivery volume per capita cannot be unlimited growth. In order to facilitate empirical fitting analysis, the above theoretical model is transformed into the logistic growth model of express delivery volume per capita, as shown in Formula 3.

$$
\mathrm{y}=\frac{\mathrm{K}_{\mathrm{L}}}{1+\mathrm{ae}^{-\mathrm{rt}}}
$$


Fitting with the method of log-linearization, the initial value of KL is determined firstly, and then the initial values of a and $R$ are calculated by linear regression. Next the final values of each parameter in the model are iterated by the method of nonlinear regression. As for the determination of the initial value of KL, the method of four-point is used to calculate the initial value of KL which is 4200 by using the express delivery volume per capita in 2007, 2011, 2013 and 2017. Then, the logarithm of the formula is obtained and the regression analysis based on the software of Excel shows that "a" equals 0.4907 and " $\mathrm{R}$ " equals 5415.389. According to the initial values of the parameters obtained above, the nonlinear regression iteration analysis of the model is carried out by using software of SPSS19.0. The iteration process and results are shown Table 1 and Table 2 respectively. Then the parameters are obtained as follows: $\mathrm{K}$ equals 235.918, $\mathrm{a}=591.965, \mathrm{r}=0.616$. The t-test is significant and the goodness of fit is excellent that the R-squared figure is 0.999. In conclusion, we get the equation of Logistic curve for the growth of express delivery volume per capita, as shown.

$$
y=\frac{235.918}{1+591.965 \mathrm{e}^{-0.616 t}}
$$

And from 2007 to 2017, the growth track of Zhejiang's express delivery industry is in line with the Logistic growth model.

Table 2. Iterative history

\begin{tabular}{|c|c|c|c|c|}
\hline \multirow{2}{*}{ Iterative number $^{\mathrm{a}}$} & \multirow{2}{*}{ the residual sum of squares } & \multicolumn{3}{|c|}{ parameter } \\
\cline { 3 - 5 } 1.0 & 693.861 & $\mathrm{~K}$ & $\mathrm{a}$ & $\mathrm{r}$ \\
\hline 1.1 & 161667.903 & -70974.772 & -89077.635 & .584 \\
1.2 & 25234.932 & -1939.485 & -6582.767 & .416 \\
1.3 & 372.342 & 4432.092 & 4871.955 & .469 \\
2.0 & 372.342 & 4432.092 & 4871.955 & .469 \\
2.1 & 271.318 & 5002.802 & 3528.553 & .429 \\
3.0 & 271.318 & 5002.802 & 3528.553 & .429 \\
3.1 & 387.114 & 3846.610 & 2159.963 & .411 \\
3.2 & 200.348 & 5086.956 & 3277.441 & .417 \\
4.0 & 200.348 & 5086.956 & 3277.441 & .417 \\
4.1 & 202.684 & 4238.516 & 2524.857 & .411 \\
4.2 & 197.372 & 4914.907 & 2966.304 & .410 \\
5.0 & 197.372 & 4914.907 & 2966.304 & .410 \\
5.1 & 194.483 & 4141.207 & 2524.409 & .411 \\
6.0 & 194.483 & 4141.207 & 2524.409 & .411 \\
6.1 & 194.781 & 2690.208 & 1688.687 & .414 \\
6.2 & 191.529 & 3449.712 & 2128.531 & .413 \\
$\ldots .$. & $\ldots \ldots$. & $\ldots \ldots$. & $\ldots \ldots$. & $\ldots \ldots$ \\
26.0 & 12.864 & 237.190 & 591.461 & .615 \\
26.1 & 12.864 & 237.190 & 591.463 & .615 \\
\hline
\end{tabular}

The derivative is calculated by numbers.

a. The principal iterative algebra is displayed on the left side of the decimal and the next is displayed on the right.

b. Since the relative reduction between the successive residual sum of squares is at most $1.00 \mathrm{E}-$ 008 , the system stops operation after 61 model evaluation and 26 derivative evaluation. 
Table 3. Estimated values of parameters

\begin{tabular}{|c|c|c|c|c|}
\hline \multirow{2}{*}{ Parameter } & \multirow{2}{*}{ Estimated value } & \multirow{2}{*}{ Standard error } & \multicolumn{2}{|c|}{$95 \%$ Confidence interval } \\
\cline { 3 - 5 } & & & LL & UL \\
\hline K & 237.190 & 14.724 & 203.236 & 271.144 \\
$\mathrm{a}$ & 591.463 & 72.551 & 424.159 & 758.766 \\
$\mathrm{r}$ & .615 & .023 & .563 & .667 \\
\hline
\end{tabular}

Calculate the key three time points on the fitting Logistic growth curve: $\mathrm{t}_{1}=\frac{\ln a-1.317}{\mathrm{r}}=8.2 \approx 9, \mathrm{t} *$ $=\frac{\operatorname{lna}}{\mathrm{r}}=10.3 \approx 11$ and $\mathrm{t}_{2}=\frac{\ln +1.317}{\mathrm{r}}=12.5 \approx 13$, which corresponds to the year of 20015,2017 and 2019 respectively.

Expanding the scope of $\mathrm{t}$ to 31 , making a forecast for the next 20 years after 2017, draw the forecast curve of express delivery volume per capita in Zhejiang Province.

Table 4. Predicted values of express delivery volume per capita

\begin{tabular}{|c|c|c|c|c|c|c|c|c|}
\hline Year & 2007 & 2008 & 2009 & 2010 & 2011 & 2012 & 2013 & 2014 \\
\hline $\begin{array}{l}\text { Express delivery volume per } \\
\text { capita }\end{array}$ & 0.7 & 1.3 & 2.5 & 4.6 & 8.3 & 15.0 & 26.4 & 44.6 \\
\hline Year & 2015 & 2016 & 2017 & 2018 & 2019 & 2020 & 2021 & 2022 \\
\hline $\begin{array}{c}\text { Express } \\
\text { delivery volume per capita }\end{array}$ & 71.1 & 104.8 & 140.9 & 173.2 & 197.7 & 214.1 & 224.1 & 229.9 \\
\hline Year & 2023 & 2024 & 2025 & 2026 & 2027 & 2028 & 2029 & 2030 \\
\hline $\begin{array}{c}\text { Express delivery volume per } \\
\text { capita }\end{array}$ & 233.2 & 235.0 & 236.0 & 236.5 & 237.0 & 237.0 & 237.1 & 237.1 \\
\hline Year & 2031 & 2032 & 2033 & 2034 & 2035 & 2036 & 2037 & \\
\hline $\begin{array}{l}\text { Express delivery volume per } \\
\text { capita }\end{array}$ & 237.2 & 237.2 & 237.2 & 237.2 & 237.2 & 237.2 & 237.2 & \\
\hline
\end{tabular}

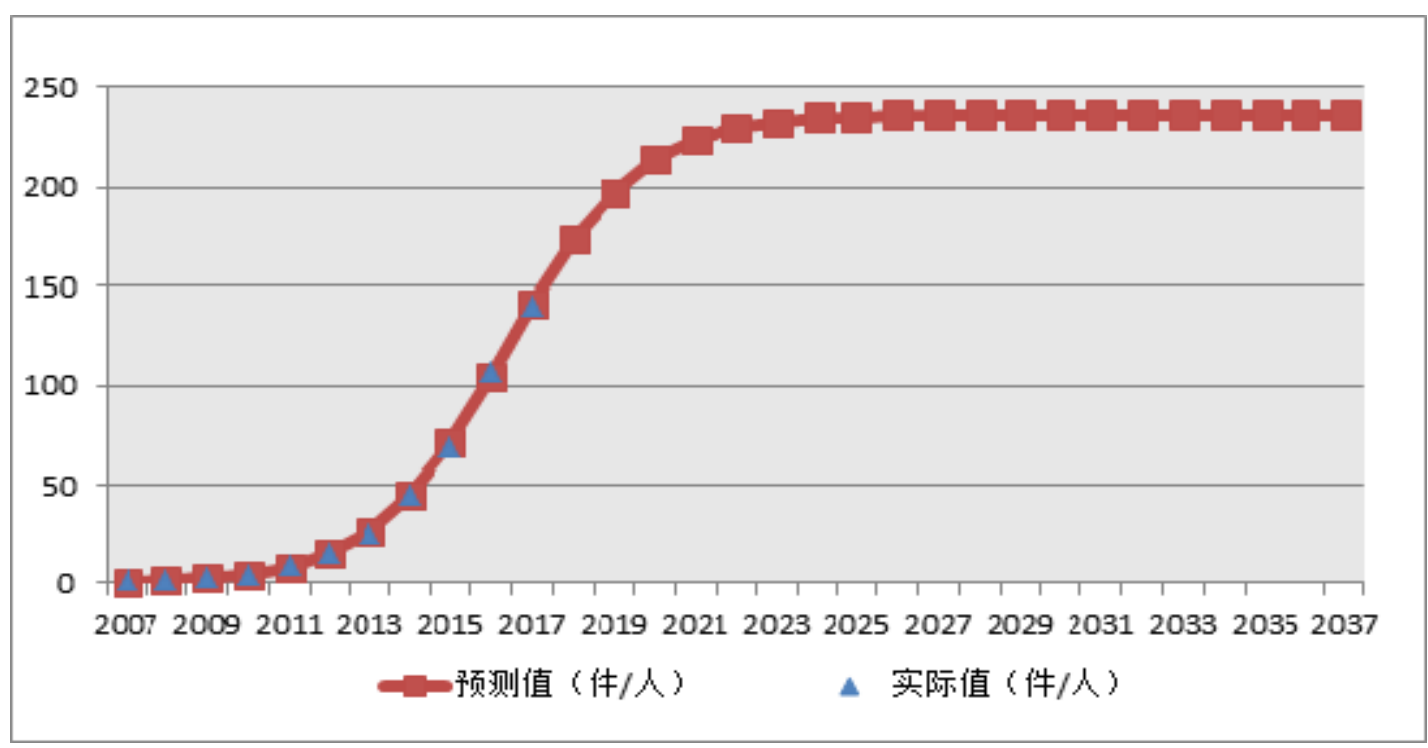

Fig. 1 Actual and predicted values of the volume of express delivery per capita 


\subsection{Analysis Results}

The initial stage of daily express delivery came into being until 2007. Before 2007, the only stateowned enterprise dominated in the express delivery industry in China and with the development of ecommerce, the private express delivery enterprises were widespread established. From 2007 to 2015, the growth rate of Zhejiang' express delivery industry was slow and it belonged to the forming stage of express delivery industry. The volume of fixed assets investment in transportation and warehousing in Zhejiang Province was small resulting in slow growth of the express delivery supply. With Alibaba, Yiwu small commodity city and many other e-commerce enterprises growing in Zhejiang, the rapid development of e-commerce drove express delivery industry to enhance service capability which has gradually attracted the attention of the government and investors. The local government issued "the '13th Five-Year plan' for the development of e-commerce industry in Zhejiang" in 2016 which stressed the importance of logistics in various aspects. From 2015 to 2017 the express delivery industry in Zhejiang Province has entered the early stage of growth. In 2017, the volume of the express delivery per capita has risen rapidly and it has been doubled compared with 2015 . At the same time, the growth rate accelerating gradually has been reached the maximum in 2017.

From 2017 onwards, the growth rate of the express delivery industry in Zhejiang Province has slowed down and entered the late growth period, which is expected to last until 2019. Under the background of the increasing demand for the express delivery, the market competition in the industry is further intensified. The number of express delivery enterprises is large, and the homogenization of service is serious leading to stringent political regulation. It is predicted that the growth rate of the volume of express delivery per capita will be further slowed down from 2019, and the industry will gradually become stable and mature for a long time. The structure of the service supply market will be basically determined, at the same time, the core competitive advantages of express delivery enterprises are basically formed and the service level will be greatly improved and basically standardized.

\section{Conclusion}

This paper makes use of the existing 11-year data of express delivery volume per capita to fit the Logistic growth model and it proves that the fitting validity is high. At present, Zhejiang' express delivery industry is in the stage of late growth when continuous improvement will be made.

The express delivery enterprises should increase investment in science and technology research of express delivery industry, enhance the level of service informatization and intelligence, and introduce differentiated and personalized service products. At the same time, relevant enterprises should innovate service categories and processes to optimize customer experience. In addition, enhance the service capabilities of "the last one kilometer" to break through the bottleneck of the express delivery industry. From the point of the government, it is necessary to formulate and implement relevant policies, industry standards, laws and regulations to guide the logistics industry in Zhejiang Province from the growth period to the mature period.

On the one hand, the deficiency is lack of the sufficient data which needs to be further expanded to carry out similar research. On the other hand, the development of Zhejiang 'express delivery industry is influenced by policies, economic environment, social status and other factors which indicates that the future development is uncertain. Whether the future development trend conforms to the Logistic curve needs be further searched.

\section{References}

[1]. Ying Huang, Ping He, Li Zhidong. Empirical Study on Product Life Cycle Based on Logistic Model [J]. Jiangsu University of science and technology (Social Science Edition), 2009,04: 5155. (Chinese). 
[2]. Quanxi Li, Yan Liu, Jialin Liu. Research on the Growth of China's Logistics Industry Based on Logistic Regression Analysis[J]. Soft Science, 2012,26 (9): 7-14.

[3]. Juan Hu, Feng Hai, Qin Liu. Identification of Stage of Logistics Industry Cluster Evolution Based on Life Cycle. Logistics Technology,2013(25): 261-265.

[4]. Huang Hao, Huang Wei. Empirical Study on Relationship between Logistics Industry and Economic Growth of Wuhan Based on Logistic Model. Logistics Technology 2015, 34(5), 197199 (in Chinese).

[5]. Liangliang Zhang. Research on the Growth Stage of Anhui's Logistics Industry- Based on Logistic Growth Model[J]. Journal of Jingchu Institute of Technology,2017,32(02):86-90+96. 